\title{
Phytohormone Profiles Induced by Trichoderma Isolates Correspond with Their Biocontrol and Plant Growth-Promoting Activity on Melon Plants
}

\author{
Ainhoa Martínez-Medina • Maria Del Mar Alguacil • \\ Jose A. Pascual • Saskia C.M. Van Wees
}

Received: 19 April 2014 / Revised: 23 June 2014 / Accepted: 1 July 2014 / Published online: 15 July 2014

(C) Springer Science+Business Media New York 2014

\begin{abstract}
The application of Trichoderma strains with biocontrol and plant growth-promoting capacities to plant substrates can help reduce the input of chemical pesticides and fertilizers in agriculture. Some Trichoderma isolates can directly affect plant pathogens, but they also are known to influence the phytohormonal network of their host plant, thus leading to an improvement of plant growth and stress tolerance. In this study, we tested whether alterations in the phytohormone signature induced by different Trichoderma isolates correspond with their ability for biocontrol and growth promotion. Four Trichoderma isolates were collected from agricultural soils and were identified as the species Trichoderma harzianum (two isolates), Trichoderma ghanense, and Trichoderma hamatum. Their antagonistic activity against the plant pathogen Fusarium oxysporum f. sp. melonis was tested in vitro, and their plant growth-promoting and biocontrol activity against Fusarium wilt on melon plants was examined in vivo, and compared to that of the commercial strain T. harzianum T-22. Several growth- and defense-related phytohormones were analyzed in the shoots of plants that were root-colonized by the different Trichoderma isolates. An increase in auxin and a decrease in cytokinins and abscisic acid content were induced by the isolates that promoted the plant growth. Principal component analysis (PCA) was used to evaluate the relationship between the plant phenotypic and hormonal variables. PCA pointed to a strong association of
\end{abstract}

A. Martínez-Medina $\cdot$ S. C. Van Wees $(\bowtie)$

Plant-Microbe Interactions, Department of Biology, Utrecht

University, H.R. Kruyt building, Padualaan 8, 3584, CH Utrecht, The

Netherlands

e-mail: S.VanWees@uu.nl

A. Martínez-Medina · M. Del Mar Alguacil · J. A. Pascual Department of Soil and Water Conservation and Organic Waste Management, CSIC-Centro de Edafología y Biología Aplicada del Segura, Campus Universitario de Espinardo, 30100 Murcia, Spain auxin induction with plant growth stimulation by Trichoderma. Furthermore, the disease-protectant ability of the Trichoderma strains against $F$. oxysporum infection seems to be more related to their induced alterations in the content of the hormones abscisic acid, ethylene, and the cytokinin transzeatin riboside than to the in vitro antagonism activity against F. oxysporum.

Keywords Biocontrol $\cdot$ Fusarium spp. · melon crop · plant hormones $\cdot$ plant growth promotion $\cdot$ Trichoderma spp.

\section{Introduction}

Different microorganisms can influence plants in different ways and have been recognized to provide promising solutions for a sustainable and environment-friendly agriculture (Berg 2009). In this context, species belonging to the genus Trichoderma are economically relevant, as they are used widely in a wide range of crop plants as biocontrol agents for the management of different pathogens and as plant growth promoters (Harman et al. 2004; Lorito et al. 2010; Monte 2001; Woo et al. 2006). Consequently, the search for Trichoderma isolates with a high antagonistic and biofertilizer potential has increased in recent years.

Most earlier studies on biocontrol of plant diseases by the rhizofungal genus Trichoderma focused on the ability of these fungi to interact directly with soil pathogens, where there was a special emphasis on the potential role of hydrolytic enzymes (such as chitinases, glucanases, and proteases) and antibiotics in mycoparasitism processes (Donzelli and Harman 2001; Ramot et al. 2000; Viterbo et al. 2002; Zeilinger et al. 1999). However, more recent findings have revealed a plantmediated effect as a major mechanism of disease control by Trichoderma; the interaction between Trichoderma and the plant triggers enhanced immunity against different pathogens 
(Martínez-Medina et al. 2013; Shoresh et al. 2010; Tucci et al. 2011). Therefore, in vitro assays for testing the biocontrol capacity of new isolates to determine their usefulness in the field have several fundamental drawbacks, as they exclude host-microbe interacting factors.

During the Trichoderma-plant interaction, the plant reprograms its transcriptome, proteome, and metabolome, resulting in an alteration of its responses to the environment, thus leading to improvement of its fitness and stress tolerance (Alfano et al. 2007; Bae et al. 2011; Marra et al. 2006; Shoresh and Harman 2008). Similar plant responses can be induced by other beneficial microorganisms, such as rhizobacteria and mycorrhizal fungi (Jung et al. 2012; Van Wees et al. 2008). Recent evidence indicates that some of the changes in the host plant upon colonization of the roots by Trichoderma are related to modifications in the relative abundance of, or sensitivity to, plant hormones (Contreras-Cornejo et al. 2011; Martínez-Medina et al. 2011; Mathys et al. 2012; Segarra et al. 2007; Shoresh et al. 2005). Increases in defenseand stress-related compounds like jasmonic acid (JA), salicylic acid (SA), and abscisic acid (ABA) have been observed in Trichoderma-colonized plants (Contreras-Cornejo et al. 2011; Martínez-Medina et al. 2011). However, the induction of direct plant defense responses by Trichoderma seems to be a time- and concentration-dependent process. Especially during early stages of the interaction, increases in SA and JA may occur, which seem to depend on the concentration of Trichoderma (Brotman et al. 2012; Hermosa et al. 2013; Segarra et al. 2007). At later stages, no enhanced levels of JA and SA are detected in general, but in different Trichoderma-plant interactions, a priming effect by Trichoderma on the activation of JA- and SA-controlled defense responses has been recorded, as evidenced by an enhanced and accelerated activation of defense mechanisms upon pathogen attack (Martínez-Medina et al. 2013; Tucci et al. 2011).

Some selected strains of Trichoderma also promote plant growth and development, possibly due to the production of growth-regulating factors by the fungus, such as auxin-like secondary metabolites (Chowdappa et al. 2013; ContrerasCornejo et al. 2009), and 1-aminocyclopropane-1-carboxylate (ACC) deaminase, which cleaves ACC, the immediate precursor of the phytohormone ethylene (Viterbo et al. 2010). In addition, recent studies have suggested an indirect altered balance of the hormones auxin and cytokinins by Trichoderma, through the induced synthesis of these hormones by the plant. Trichoderma inoculation of Prunus and cherry rootstocks induced an increase in indole-3-acetic acid (IAA) whereas zeatin was decreased (Sofo et al. 2011, 2012).

Success of a given microbial isolate as a biological control agent depends on a number of properties, such as mycoparasitic activity, rapid growth rate, capability to utilize various substrates, and production of antibiotics and extracellular hydrolytic enzymes. Moreover, the ability to boost plant defenses and the capacity for improving plant growth and yield are important characteristics as well for the selection of microbial isolates for agricultural use. To optimize the exploitation of new beneficial isolates and to enhance their practical application it is imperative to extend the knowledge on the mechanisms of the interaction of Trichoderma with the host plant and (in) directly with phytopathogens. In the present study, four Trichoderma isolates were collected from agricultural soil and were evaluated both with in vitro and in vivo assays by using the agriculturally and economically important crop melon. Their performance was compared with the commercial T. harzianum strain T-22. To improve our understanding of the mechanisms involved in the plantmediated protective and growth promotional effects, we explored the accumulation of several phytohormones in the host during the interaction with the different Trichoderma isolates. Principal component analysis (PCA) was used to gain insight about the possible contribution of the alteration in hormonal signature to the biocontrol and growth-promoting effect of Trichoderma.

\section{Methods and Materials}

Identification of Trichoderma Isolates The four new Trichoderma strains that were studied were isolated from soil samples collected from agricultural fields on which different horticultural crops were grown rotationally in a semi-arid Mediterranean area of South-East Spain (average annual rainfall of $300 \mathrm{~mm}$, mean annual temperature of $20{ }^{\circ} \mathrm{C}$ ), where disease patches caused by Fusarium sp. had been observed. The isolation was performed using Rose Bengal agar medium. Putative Trichoderma colonies were purified by two rounds of subculturing on potato dextrose agar (PDA, Scharlau Chemie, Barcelona, Spain). In addition, the commercial strain T. harzianum T-22 (Harman 2000) also was used. Monoconidial cultures of all isolates were prepared by plating diluted conidial suspensions onto Trichoderma semi-selective medium (Papavizas and Lumsden 1982). For molecular identification, genomic fungal DNA was extracted from $100 \mathrm{mg}$ of fresh mycelium of each isolate grown on PDA at $28^{\circ} \mathrm{C}$ for $6 \mathrm{~d}$ by using the DNeasy plant mini Kit following the manufacturer's recommendations (Qiagen). PCR amplification of the internal transcribed spacer (ITS) region of rDNA of fungal isolates was carried out with universal primer pair ITS1 and ITS4 (560 bp product size) (White et al. 1990). PCR reactions were carried out in a final volume of $25 \mu$ using 'ready to go' PCR beads (Amershan Pharmacia Biotech), $0.2 \mu \mathrm{M}$ dNTPs and $0.5 \mu \mathrm{M}$ of each primer (PCR conditions: $95^{\circ} \mathrm{C}$ for $5 \mathrm{~min}$, then 35 cycles at $95{ }^{\circ} \mathrm{C}$ for $1 \mathrm{~min}, 54{ }^{\circ} \mathrm{C}$ for $1 \mathrm{~min}, 72{ }^{\circ} \mathrm{C}$ for $1 \mathrm{~min}$ and $30 \mathrm{~s}$, then $72{ }^{\circ} \mathrm{C}$ for $10 \mathrm{~min}$ ). The PCR products were purified using a Gel extraction Kit (Qiagen). Sequencing 
was done by the Molecular Biology Laboratory (SACEMurcia University, Spain). Sequence editing was done with the program Sequencer version 4.1.4 (Gene Codes Corporation). A search for similar sequences to the ones from this study was conducted with the BLAST tool (Zhang et al. 2000) provided by GenBank (NCBI). The sequences have been deposited at the NCBI GenBank (http://www.ncbi.nlm.nih. gov) with accession numbers FR872738-FR872741. Phylogenetic analysis was carried out on the sequences obtained here and on thirty-six corresponding to both the closest matches from NCBI, as well as on sequences representatives of the major species of Trichoderma. All sequences were aligned by using the multiple sequence comparasion program, MAFFT, version 7.0, and the alignment was adjusted manually in BioEdit software version 7.0.4.1 (Hall 1999). Maximum likelihood (ML) phylogenetic analyses were performed with MEGA v.5.05 software (Tamura et al. 2011). Nucleotide data files were first tested to find the best DNA evolution model. The Tamura 3-parameter model with a discrete Gamma distribution showed the lowest BIC scores (Bayesian Information Criterion) and was deemed to best describe the nucleotide substitution pattern. Initial tree(s) for the heuristic search were obtained by applying the Neighbor-Joining method to a matrix of pairwise distances estimated by using the Maximum Composite Likelihood (MCL) approach. The robustness of all trees obtained was evaluated by 1,000 bootstrap replications. There were a total of 480 positions in the final dataset.

Host Plant and Fungal Inocula Melon plants (Cucumis melo cv. Giotto) were used as hosts. The different Trichoderma inocula were produced by using a specific solid medium prepared by mixing commercial oat, bentonite, and vermiculite according to Martínez-Medina et al. (2009b). Monoconodial F. oxysporum f. sp. melonis was isolated from infected melon plants cultivated in a seedling nursery in Murcia (Spain). For the production of the pathogen inoculum, F. oxysporum was cultivated for $5 \mathrm{~d}$ on potato dextrose broth (Scharlau Chemie, Barcelona, Spain), amended with $100 \mathrm{mg}^{-1}$ streptomycin sulfate, at $28^{\circ} \mathrm{C}$ in darkness at $120 \mathrm{rpm}$ (Martínez-Medina et al. 2009b). After the incubation period, the fungal culture was centrifuged at $193 \times g$, resuspended in sterile water, and centrifuged again. The fungal suspension contained $1 \times 10^{8}$ conidia $\mathrm{ml}^{-1}$.

In vitro Growth Rates and Antagonism Assay The mycelial growth rate of each Trichoderma isolate was determined by measuring mycelial radial growth of cultures grown on PDA dishes at $28^{\circ} \mathrm{C}$ each $24 \mathrm{~h}$. For the in vitro antagonism assays, two PDA discs $(5 \mathrm{~mm})$ of the $F$. oxysporum culture and the Trichoderma culture were placed $4 \mathrm{~cm}$ apart on a PDA plate and incubated at $28{ }^{\circ} \mathrm{C}$ for $7 \mathrm{~d}$. A control with $F$. oxysporum only was placed in a Petri dish without the Trichoderma culture. The percentage of inhibition of $F$. oxysporum by
Trichoderma was calculated as following: I=100-(100R2/ $\mathrm{R} 1$ ), where I is the inhibition of vegetative growth of F. oxysporum, $\mathrm{R} 1$ the radius of the colony of the pathogen in the control plates in $\mathrm{mm}$, and $\mathrm{R} 2$ the radius of the colony of the pathogen grown in the presence of Trichoderma. The capacity of the isolates to colonize the $F$. oxysporum culture was determined according to Ortiz and Orduz (2000), using the colonization ability scale: 0 , no invasion of the $F$. oxysporum colony by Trichoderma; 1 , invasion of $25 \%$ of the F. oxysporum colony surface area; 2, invasion of $50 \%$, invasion of $100 \%$; invasion of $100 \%$ of the F. oxysporum colony surface area by Trichoderma and sporulation of Trichoderma. Assays were conducted three times.

In vivo Analysis of Plant Growth and Biocontrol Activity Melon plants were tested in vivo in a completelyrandomized experimental design with 30 replicates per treatment in a seedling nursery. Different treatments were prepared by mixing sterilized commercial peat $\left(0.37 \mathrm{~g} \mathrm{~kg}^{-1} \mathrm{~N}\right.$ total, $1.158 \mathrm{mg} \mathrm{kg}^{-1}$ available $\mathrm{P}$, and $1.34 \mathrm{mg} \mathrm{kg}^{-1}$ available $\mathrm{K}$ ) with the Trichoderma inocula to reach population densities of $1 \times$ $10^{6}$ conidia $^{-1}$ of peat (Martínez-Medina et al. 2009a). Melon seeds were sown (one seed/well) in the different peatTrichoderma mixtures and covered with vermiculite in polystyrene trays. Seedlings were grown using standard nursery culture conditions, which included germination in a controlled-environment germination chamber until seedling emergence $\left(28^{\circ} \mathrm{C}\right.$ and $90-95 \%$ humidity). After $60 \mathrm{~h}$, the trays with the seedlings were placed on rails in a polyethylenecovered seedling nursery with natural daylight conditions. Plants were watered daily. Seven weeks after sowing, half of the experiment (15 replicates of each treatment) was harvested. Shoot and roots were separated, and their fresh weights determined as a measure of plant growth. The number of true leaves was recorded. The aerial part of the plant was frozen immediately in liquid $\mathrm{N}_{2}$ and stored at $-80^{\circ} \mathrm{C}$. The remaining 15 replicates of each treatment were inoculated on the substrate with $2 \mathrm{ml}$ of a $F$. oxysporum conidial suspension to achieve a final concentration of $1 \times 10^{4}$ conidia $\mathrm{g}^{-1}$ of peat in order to study the Fusarium wilt incidence. Three weeks after pathogen inoculation, plants were harvested, and disease incidence was evaluated by harvesting the most basal segment of the stem $(\sim 1.5 \mathrm{~cm})$, surface sterilizing it by soaking it in $1 \%$ sodium hypochlorite for $5 \mathrm{~min}$, and rinsing it with sterile water. The segments were subsequently incubated on PDA plates at $28{ }^{\circ} \mathrm{C}$ for $6 \mathrm{~d}$ and the appearance of $F$. oxysporum colonies was considered to be indicative of infection. The percentage of infected plants was used as a measure for disease incidence. All assays were conducted twice.

Hormone and ACC Extraction and Analysis Zeatin (transzeatin, Z), zeatin riboside (trans-zeatin riboside, ZR), indole3-acetic acid (IAA), 1-aminocyclopropane-1-carboxylic acid 
(ACC), abscisic acid (ABA), salicylic acid (SA), and jasmonic acid (JA) were extracted from one gram of fresh plant shoot (leaves and stems) and purified according to Albacete et al. (2008). The analyses were carried out on an HPLC/MS system consisting of an Agilent 1,100 Series HPLC (Agilent Technologies, Santa Clara, CA, USA) equipped with a micro-well plate autosampler and a capillary pump connected to an Agilent Ion Trap XCT Plus mass spectrometer (Agilent Technologies, Santa Clara, CA, USA) using an electrospray (ESI) interface. Mass spectra were obtained using the DataAnalysis program for LC/MSD Trap Version 3.2 (Bruker Daltonik, GmbH, Germany). For quantification of IAA, Z, ZR, ABA, SA, and JA, calibration curves were generated for each component analyzed $(0.05,0.075,0.1$, 0.2 , and $0.5 \mathrm{mg} \mathrm{L}^{-1}$ ) and corrected for $0.1 \mathrm{mg} \mathrm{L}^{-1}$ internal standards: $\left[{ }^{2} \mathrm{H}_{5}\right]$ trans-zeatin, $\left[{ }^{2} \mathrm{H}_{6}\right]$ cis,trans-abscisic acid and $\left[{ }^{2} \mathrm{H}_{5}\right]( \pm$ )-jasmonic acid (Olchemin Ltd., Olomouc, Czech Republic), and $\left[{ }^{13} \mathrm{C}_{6}\right]$ indole-3-acetic acid (Cambridge Isotope Laboratories Inc., Andover, MA, USA). ACC was quantified by the external standard method using the same concentration range (purchased from Sigma-Aldrich). Recovery percentages ranged between $92 \%$ and $95 \%$. All samples were run in triplicate.

Statistical Analysis The data were subjected to analysis of variance (ANOVA) using SPSS software version 19.0 (SPSS Inc., Chicago, IL, USA). Statistical significance was determined by Tukey's multiple-range tests $(P<0.05)$. A Dunnett's test was performed to compare the level of shoot phytohormones of each treatment with the control. Principal component analysis (PCA) was conducted by using the SPSS software package. For the extraction of principal component, the correlation matrix extraction method was used. The relations between the biocontrol ability and in vitro measurements of Trichoderma were analyzed by linear correlation analysis between the wilt incidence and the in vitro measurements.

\section{Results}

Identification of the Trichoderma Isolates In order to identify novel Trichoderma isolates with high biocontrol and growth promotion capacities, 4 Trichoderma isolates were isolated from soil samples collected from agricultural fields on which different horticultural crops in rotation had grown and where disease patches caused by Fusarium sp. had been observed. Isolates were identified through sequencing a portion from the 5.8S gene and the flanking ITS1 and ITS4 regions. The BLAST search revealed that sequences from the 4 isolates and from the commercial strain T. harzianum $\mathrm{T}-22$ had a high degree of similarity (99-100 \% similarity) to sequences from other Trichoderma species deposited in the NCBI database.
Phylogenetic analysis separated our Trichoderma isolates into three different clades that were supported by a bootstrap value of $99 \%$ (Fig. 1). Isolates T-4, T-7, and T-22 grouped together with sequences of Hypocrea lixii/Trichoderma harzianum. Isolate T-10 was closely related to sequences of $T$. ghanense, and T-17 to T. hamatum (Fig. 1).

In vitro Growth Rates and Antagonistic Activity Against Fusarium oxysporum At $28^{\circ} \mathrm{C}$, the natural isolates generally showed mycelial growth to the same extent as the commercial strain $T$. harzianum $\mathrm{T}-22$, except for $T$. hamatum $\mathrm{T}-17$, whose growth lagged somewhat behind (Table 1). To investigate the capacity of the different isolates to inhibit $F$. oxysporum, both species were cultivated together on PDA medium. All tested isolates inhibited F. oxysporum mycelial growth, but the commercial strain T. harzianum T-22 exhibited the strongest inhibitory effect (Table 1). There was no strict correlation between the strains' in vitro antagonistic activities against F. oxysporum and the growth capabilities of Trichoderma (Table 1). For example, strain T-17 did not show the lowest inhibition of $F$. oxysporum growth. This indicates that differences in in vitro antagonism by Trichoderma are possibly also related to the secretion of inhibiting metabolites or volatiles. After 7 days, all Trichoderma isolates had overgrown the colony of $F$. oxysporum, albeit to differing degrees. Isolate T. harzianum $\mathrm{T}-22$ had colonized the pathogen completely and even exhibited sporulation on it (Table 1). Isolates T-7, T-10 and T-17 exhibited $50 \%$ invasion of the $F$. oxysporum colony surface, while T-4 displayed the least invasion, covering up to $25 \%$ of the F. oxysporum colony surface.

Effect of Trichoderma Isolates on Melon Plant Growth In order to determine their capacity to promote plant growth, the different Trichoderma isolates were assayed in a commercial seedling nursery. After 7 weeks of cultivation, both T. ghanense T-10 and the commercial strain T. harzianum T-22 had stimulated both shoot and root weights, but the effect by T-22 was the greatest (Fig. 2a, b). Isolate T-17 promoted root weight only. The isolates T-4 and T-7 had no plant growth promoting effect (Fig. 2a, b). In agreement with the increased fresh weight of the plants, treatment with isolates T-10 or T-17 resulted in a higher number of true leaves compared to the untreated controls (Fig. 2c), but commercial strain T-22 had a greater effect on leaf formation. The differences in the ability for growth improvement among the different isolates were not related to different root colonization capacities, because the number of Trichoderma colony-forming units in the rhizosphere of the melon plants, as determined after 7 weeks, was similar to initial inoculation values for all different isolates (data not shown).

Ability of Trichoderma Isolates to Control Fusarium Wilt in Melon To examine the capacity of the Trichoderma isolates for Fusarium wilt reduction, 7-week-old plants treated with 
Fig. 1 Phylogenetic tree of the Trichoderma isolates based on the ITS-rDNA sequences

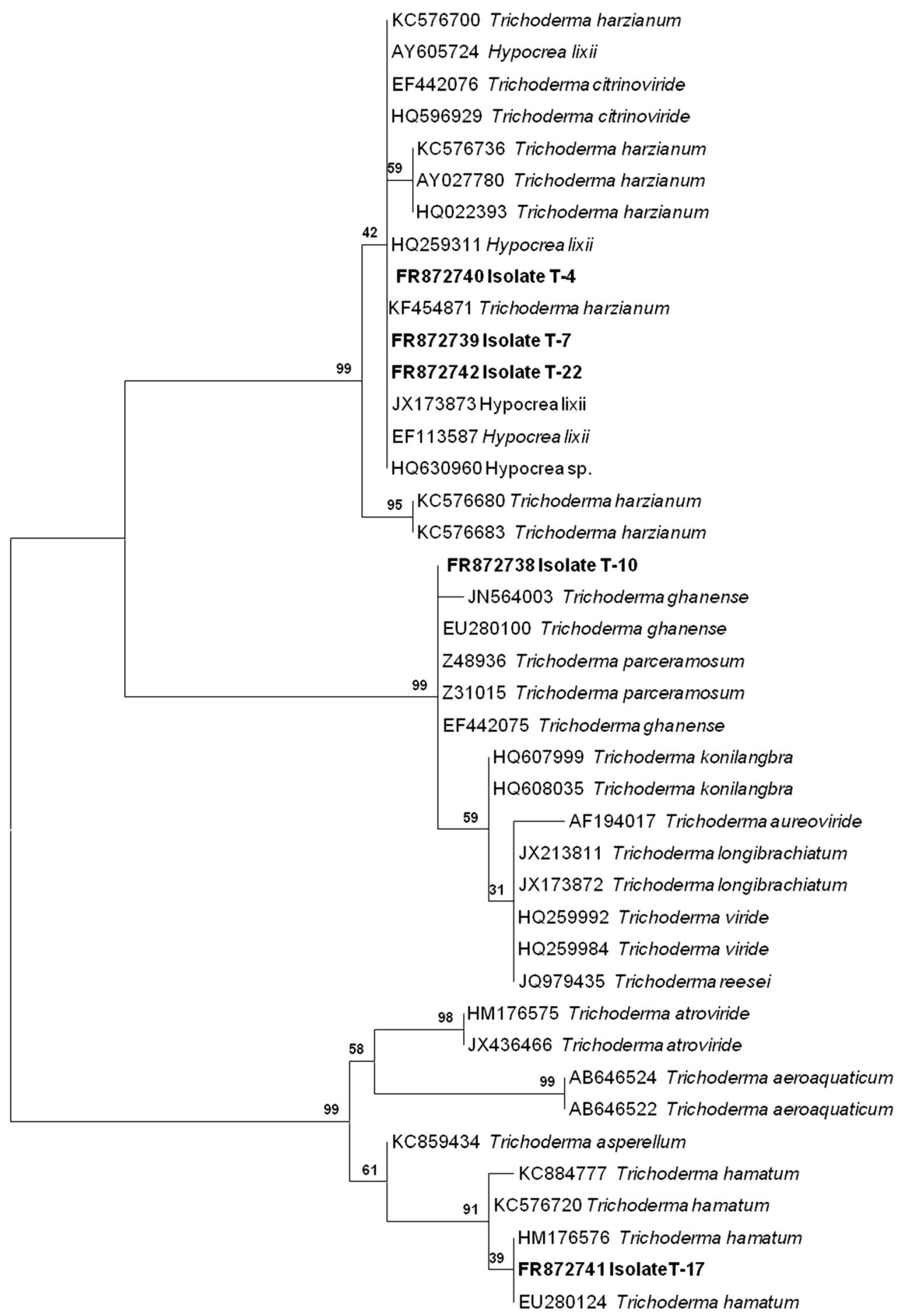

5

the Trichoderma isolates and grown in a commercial greenhouse were inoculated artificially with the soil-borne pathogen F. oxysporum, and the wilt incidence was evaluated at 3 weeks. The isolates T-4, T-7, and T-17 were equally effective in controlling disease incidence, while isolate $\mathrm{T}-10$ that showed the highest inhibition on $F$. oxysporum growth in vitro, exhibited a lesser ability to reduce the wilt incidence (Fig. 2d).
Plants inoculated with the commercial strain T-22 showed the lowest level of wilt incidence.

Impact of Trichoderma Inoculation on Hormone Levels in the Shoots of Melon Plants The impact of Trichoderma sp. inoculation on the amount of the growth- and defense-related phytohormones IAA, Z and ZR, ABA, SA, JA, and the 
Table 1 Radial growth $\left(\mathrm{mm} \mathrm{d}^{-1}\right)$ of Trichoderma isolates; in vitro antagonistic activity of the Trichoderma isolates against Fusarium oxysporum and degree of $F$. oxysporum colonization by the Trichoderma isolates

\begin{tabular}{llll}
\hline Trichoderma isolate & Radial growth & F. oxysporum Inhibition & F. oxysporum Colonization \\
\hline T. harzianum T-4 & $8.3 \mathrm{a}$ & $55 \% \mathrm{bc}$ & 1 \\
T. harzianum T-7 & $6.6 \mathrm{~b}$ & $42 \% \mathrm{~d}$ & 2 \\
T. ghanense T-10 & $8 \mathrm{a}$ & $61 \% \mathrm{~b}$ & 2 \\
T. hamatum T-17 & $5 \mathrm{c}$ & $51 \% \mathrm{c}$ & 2 \\
T. harzianum T-22 & $7.5 \mathrm{ab}$ & $75 \% \mathrm{a}$ & 4 \\
\hline
\end{tabular}

Mycelial growth rate was calculated at $28^{\circ} \mathrm{C}$ on PDA dishes

(a) Percentage of inhibition was calculated as: $I=100-(100 R 2 / R I)$, where $I$ is the inhibition of vegetative growth of $F$. oxysporum, $R I$ the radius of the colony of the pathogen in the control plates in $\mathrm{mm}$, and $R 2$ the radius of the colony of the pathogen grown in the presence of Trichoderma

(b) Colonization ability scale: Charge to the same as in materials: 0 , no invasion of the $F$. oxysporum colony by Trichoderma; 1 , invasion of $25 \%$ of the F. oxysporum colony surface area; 2 , invasion of $50 \%$; 3 , invasion of $100 \%$; , invasion of $100 \%$ of the $F$. oxysporum colony surface area by Trichoderma and sporulation of Trichoderma

Means followed by the same letter within each column are not significantly different $(P<0.05)$ according to Tukey's test $(N=10)$

ethylene precursor ACC was determined in the shoots of melon plants of which the roots had been treated with the Trichoderma isolates. Compared to control plants, levels of IAA were significantly higher in plants inoculated with the natural isolates T-10, T-17, and T-22 (Fig. 3a), whereas they were not altered in plants treated with isolates T-4 and T-7. None of the Trichoderma isolates significantly impacted the $\mathrm{Z}$ levels in the melon plants (Fig. 3b), but all of them reduced the ZR levels significantly by $50 \%$ (Fig. 3c); combining the observations for $\mathrm{Z}$ and $\mathrm{ZR}$, which depicts the total amount of cytokinins $(Z+Z R)$, illustrates that cytokinin is decreased in melon plants colonized by T-10, T-17, and T-22 (Fig. 3d).
The levels of ABA were significantly decreased in plants colonized by T-10, T-17, and T-22 (Fig. 4a), whereas they did not change upon colonization by T-4 and T-7. ACC levels were reduced by $\mathrm{T}-4, \mathrm{~T}-7$, and $\mathrm{T}-22$, which are all T. harzianum species, whereas $\mathrm{T}-10$ and $\mathrm{T}-17$ did not affect ACC concentration (Fig. 4b). Finally, no significant modification was observed in the SA or JA levels of plants treated with any of the Trichoderma isolates (Fig. 4c, d).

Principal Component Analysis To assess whether the different phytohormonal signatures that were induced in the melon plants by the five tested Trichoderma strains are associated with their effects on the plant phenotypic parameters that we
Fig. 2 Effect of inoculation of Trichoderma natural isolates T. harzianum T-4, T. harzianum $\mathrm{T}-7, T$. ghanense $\mathrm{T}-10$, and T. hamatum $\mathrm{T}-17$ and the commercial isolate $T$. harzianum $\mathrm{T}-22$ on melon plant growth and Fusarium wilt incidence. Shoot a and root $\mathbf{b}$ fresh weights (in grams) and number of true leaves c of melon plants inoculated with Trichoderma isolates. d

Percentage of Fusarium wilt incidence in melon plants after 3 wk of challenge with

F. oxysporum. Bars indicate the SE of fifteen replicates. Columns not sharing a letter in common differ significantly $(P<0.05)$ according to Tukey's test
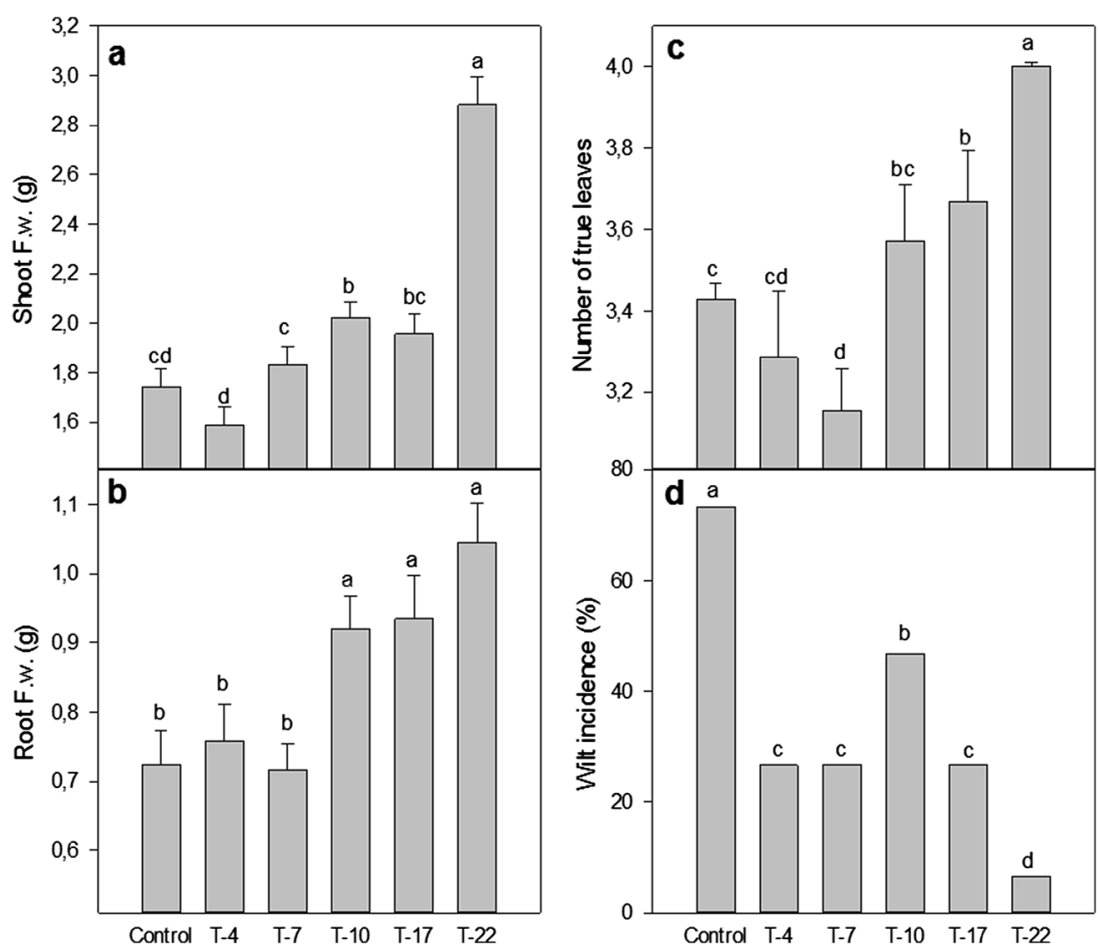
Fig. 3 Content of indole-3-acetic acid (IAA) a, zeatin (Z) b, zeatin riboside $(Z R) \mathbf{c}$ and total cytokinin measured $(Z+Z R) d$ in shoots of melon plants that were root-inoculated with Trichoderma natural isolates T. harzianum T-4, T. harzianum T-7, $T$. ghanense T-10, and T. hamatum T-17, and the commercial isolate

T. harzianum T-22. Data are the means of three replicates $(+\mathrm{SE})$. Asterisks indicate that means are significantly different from the control according to Dunnett's test $(P<0.05)$
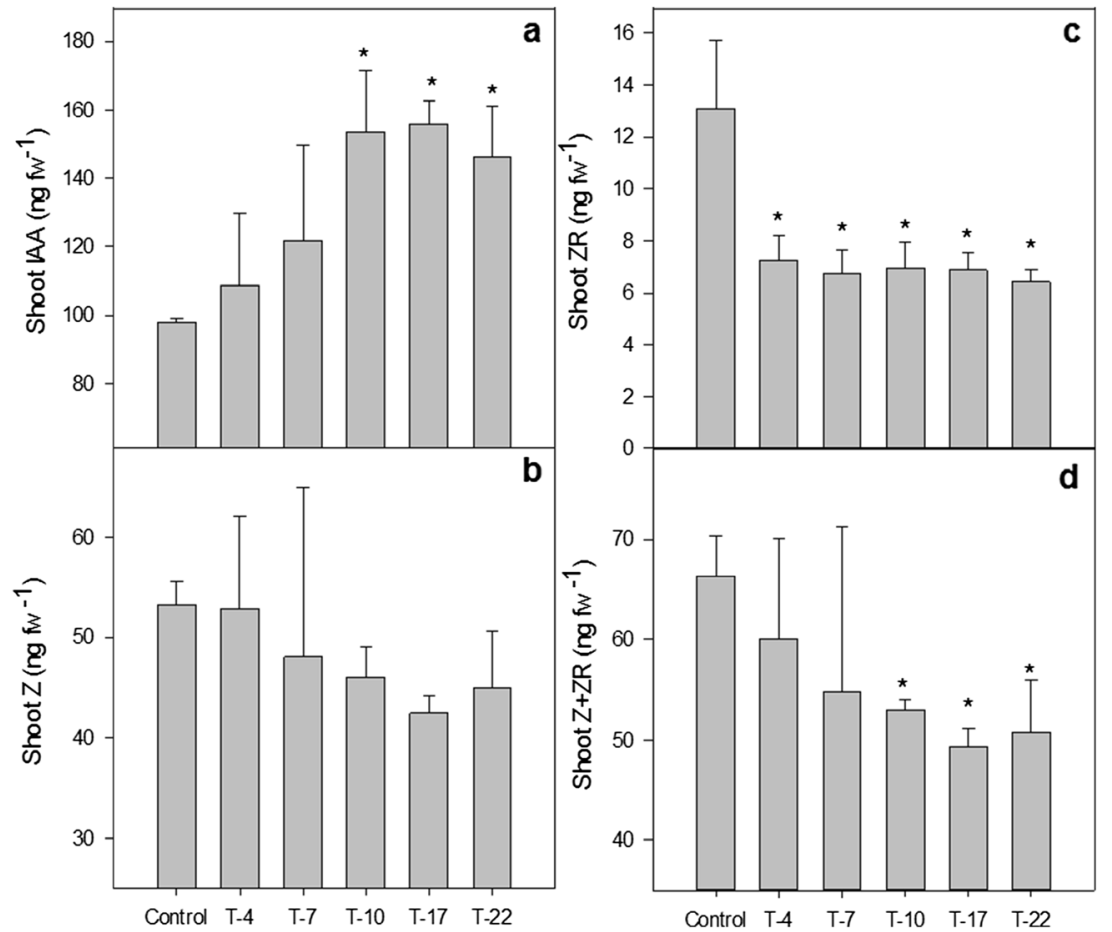

measured, a principal component analysis (PCA) was performed. PCA has proven to be a powerful method to understand hormonal profiling experiments, especially when they show a high degree of correlation (Albacete et al. 2010). As plant physiological processes are usually influenced by the complex balance between various hormones, the hormonal ratios IAA/Z+ZR, IAA/ABA, Z+ZR/ABA, Z+ZR/ACC, IAA/ACC, and ACC/ABA also were included in the PCA analysis. The phenotypic processes measured were shoot and root weight, number of true leaves, and Fusarium wilt incidence. PCA explains $65 \%$ of the variation between the treatments with two major principal components, PC1 (44,5\%) and PC2 (20\%) (Fig. 5). Most of the hormonal parameters were strongly associated in three clusters (enclosed within the circles). Shoot and root weight, and number of true leaves were placed in the same cluster as
Fig. 4 Content of abscisic acid (ABA) a,1-aminocyclopropane1-carboxylic acid (ACC) b, salicylic acid (SA) c, and jasmonic acid (JA) d in shoots of melon plants that were rootinoculated with Trichoderma natural isolates T. harzianum T-4, T. harzianum T-7, T. ghanense $\mathrm{T}-10$, and T. hamatum T-17, and the commercial isolate

T. harzianum T-22. Data are the means of three replicates $(+\mathrm{SE})$. Asterisks indicate that means are significantly different from the control according to Dunnett's test $(P<0.05)$
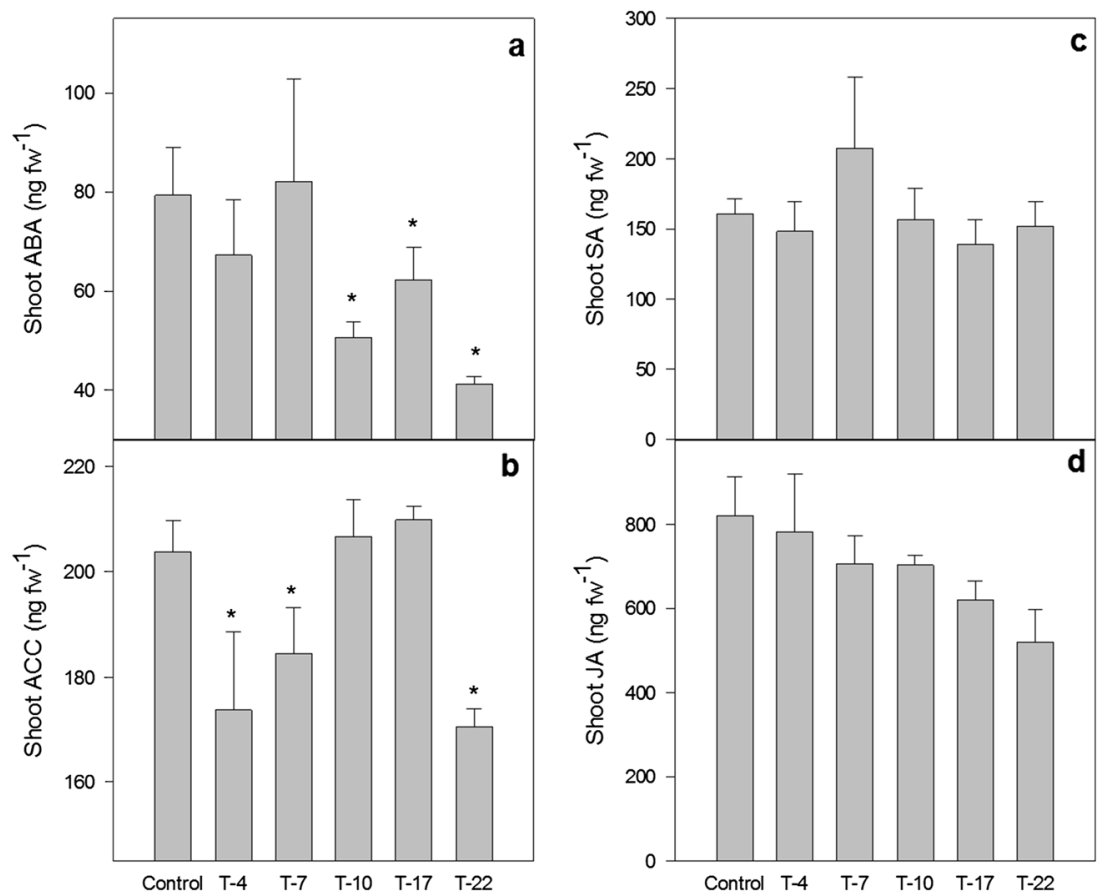
Fig. 5 Two axes principal components (PC1, PC2) analysis showing the physiological measurements shoot and root weight, number of true leaves and Fusarium wilt incidence, and the position of the hormonal variables indole-3-acetic acid (IAA), zeatin $(\mathrm{Z})$, zeatin riboside $(\mathrm{ZR})$, total cytokinin measured $(\mathrm{Z}+\mathrm{ZR})$, abscisic acid (ABA), 1aminocyclopropane-1-carboxylic acid (ACC) and the hormonal ratios IAA/Z+ZR, IAA/ABA, $\mathrm{Z}+\mathrm{ZR} / \mathrm{ABA}, \mathrm{Z}+\mathrm{ZR} / \mathrm{ACC}, \mathrm{IAA} /$ $\mathrm{ACC}$, and $\mathrm{ACC} / \mathrm{ABA}$ induced by the Trichoderma isolates

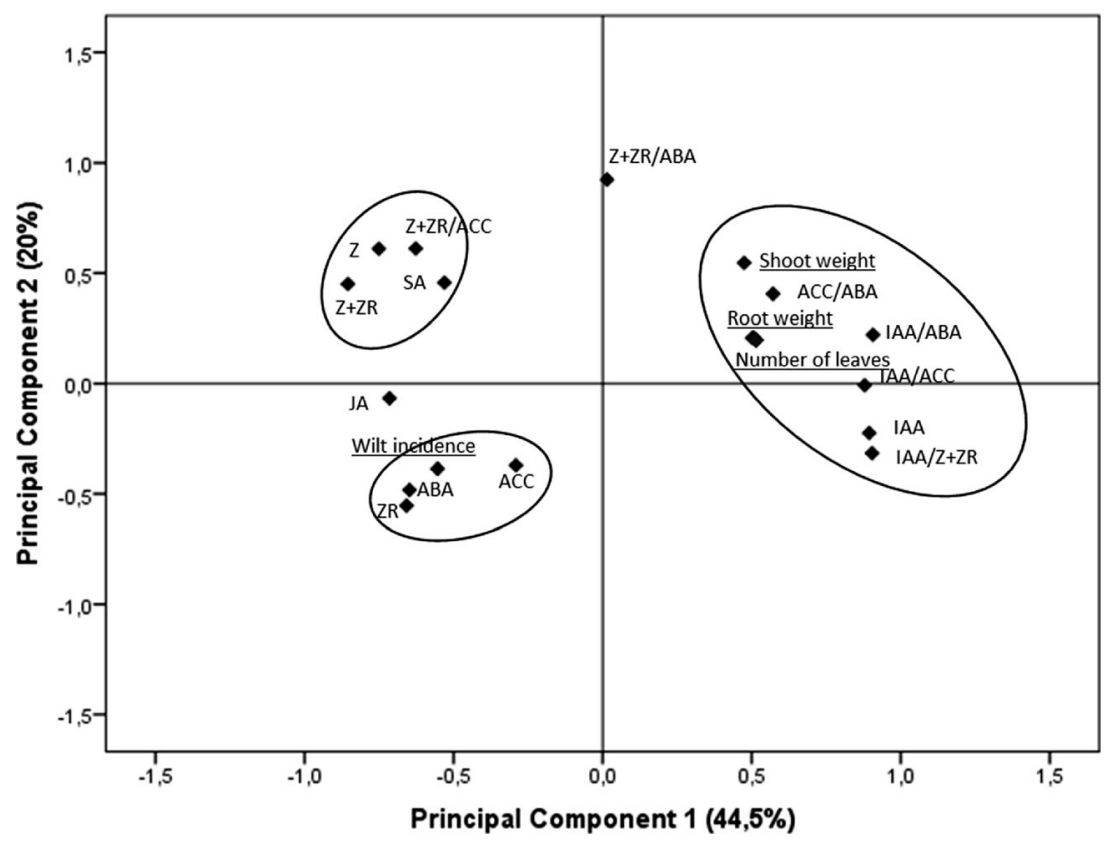

IAA, and the IAA-related ratios IAA/ABA, IAA/(Z+ZR), and IAA/ACC, and strongly positively loaded in the PC1, which suggest the physiological importance of IAA increase by Trichoderma colonization in enhancing plant growth in general. The hormonal parameters $\mathrm{Z}, \mathrm{Z}+\mathrm{ZR}, \mathrm{Z}+\mathrm{ZR} / \mathrm{ACC}$ were associated in a distinct cluster that also was strongly loaded in PC1, but was not associated with any of the phenotypic parameters tested. Disease incidence was placed in the same cluster as the hormones ZR, ABA, and ACC. This result suggests that the regulation of these specific hormones could contribute to the biocontrol activity of the tested Trichoderma strains. Linear correlation analysis showed no significant correlation $(P>0.05)$ between the disease incidence and the in vitro antagonism activity (data not shown).

\section{Discussion}

Trichoderma spp. are among the most widely used commercial biofungicides in the world (Harman 2000). There is a growing large body of literature describing their protective effects against different necrotroph and (hemi-) biotrophic fungal pathogens and their growth-promoting ability (Harman et al. 2004; Shoresh et al. 2010). The selection of Trichoderma isolates for agricultural use has been largely based on their performance in in vitro assays, mainly searching for lytic enzymes capable of hydrolyzing the cell wall of phytopathogenic fungi (Harman et al. 2008). However, selected Trichoderma isolates also are able to improve plant growth and disease resistance through manipulating the phytohormone regulatory network in the plant (Hermosa et al.
2013). Accordingly, screening procedures for selection of new beneficial isolates should include not only in vitro assays, but also take into consideration the multitrophic interactions, including the interactions established by the microbe with the plant host. In this study, the four Trichoderma isolates were collected from agricultural soils and evaluated both in vitro and in vivo for their potential as biocontrol agents against Fusarium wilt of melon seedlings. The best natural isolate in the in vitro study was the isolate T. ghanense T-10. However, it did not outperform the commercial strain T. harzianum T-22 regarding the antagonism towards $F$. oxysporum. Trichoderma harzianum is a species that can be highly efficient as a mycoparasite (Benhamou and Chet 1996; Elad et al. 1983). It has been reported that this species produces a large battery of hydrolytic enzymes when growing in the presence of F. oxysporum cell walls (López-Mondéjar et al. 2011). However, the natural isolates T. harzianum T-4 and T-7 were the least effective in antagonizing $F$. oxysporum growth, indicating that the antagonistic ability of the different strains is highly dependent on the isolate and not on the species. Accordingly, Anees et al. (2010) previously showed that antagonism is not a property of a Trichoderma species, as different strains of the same species can exhibit varying potentials of biocontrol.

In general, all strains showed in vitro antagonism of F. oxysporum and also reduced Fusarium wilt disease on melon plants. However, such in vitro observations can be a false predictor of biocontrol activity in vivo. As an example, isolate T-17 shows a moderate inhibition of $F$. oxysporum growth and low colonization of the pathogen, but actually efficiently controls the wilt disease. Several authors have pointed out the inability of in vitro plate tests to screen for 
potential biocontrol microbes to be used in the field, which can be either due to the lack of interaction between plants and the rhizosphere environment (Blaya et al. 2013), the Trichoderma-plant interaction (Martínez-Medina et al. 2011), or the fact that it is difficult for many Trichoderma species to express fungal secondary metabolite genes under standard laboratory conditions (Mukherjee et al. 2012). Our results highlight the need to use a functional approach including in vivo experiments to screen for biocontrol isolates.

Whereas all natural isolates tested exhibited biocontrol capacity, only two of them, T-10 and T-17, stimulated plant growth and development. Several Trichoderma isolates have shown the ability for increasing plant growth by improving plant ability for nutrient uptake (Martínez-Medina et al. 2009a) and through the secretion of growth-promoting metabolites (Chowdappa et al. 2013; Contreras-Cornejo et al. 2009). According to Sofo et al. (2011), this phenomenon could be steered by Trichoderma, which would benefit from a greater root system for colonization, thus reinforcing symbiotic behaviors with the plants.

A number of explanatory mechanisms for plant growth promotion and disease resistance induced by Trichoderma have been proposed (Benítez et al. 2004; Harman et al. 2004; Lorito et al. 2010; Vinale et al. 2008). Among them, studies on the interaction of the biocontrol agent with the hormonal network within the plant are limited despite auxin, cytokinin, abscisic acid, and ethylene being major players in plant growth and in fitness (Linkies et al. 2009; Mok and Mok 2001; Raghavendra et al. 2010; Simon and Petrasek 2011). IAA is the most abundant naturally occurring auxin in vascular plants, and it is known to play a major role in lateral and adventitious root initiation and emergence and in shoot development (Simon and Petrasek 2011). In our study, IAA levels were increased by the Trichoderma isolates that also promoted plant growth, which might explain, at least in part, the growthpromoting effect observed (Figs. 2a, b, c and 3a). Furthermore, in the PCA, the physiological variables related to plant growth were strongly positively associated with different IAA related measurements, suggesting a role for IAA in controlling plant growth stimulation by Trichoderma. Accordingly, another growth-promoting strain $T$. harzianum T-78 previously has been shown to increase IAA plant levels (Martínez-Medina et al. 2011). Contreras-Cornejo et al. (2009) demonstrated that promotion of Arabidopsis thaliana growth by Trichoderma virens operates through the classical auxin response pathway, due to production of IAA and auxinlike compounds. Different Trichoderma isolates have been reported to produce and release in the culture medium auxinrelated compounds (Chowdappa et al. 2013; Gravel et al. 2007). In contrast, Sofo et al. (2012) did not detect hormone production by $T$. harzianum T-22 in axenic growing media, suggesting that $\mathrm{T}-22$ is able to induce hormone synthesis $e x$ novo in the plants, probably through the up-regulation of plant genes for hormone biosynthesis or the down-regulation of the genes involved in hormone catabolism. In our case, as we did not determine the ability of the natural isolates to produce hormones in axenic growth media, it is not known if the increased IAA content observed originated from production by the fungi or the plant.

Other well known hormonal regulators of plant growth and development are cytokinins (Mok and Mok 2001). They promote shoot growth but inhibit root growth (Werner et al. 2001). In our study total cytokinins measured $(Z+Z R)$ were reduced in shoots of plants colonized by isolates $\mathrm{T}-10$ and $\mathrm{T}-17$, and $\mathrm{T}-22$, which were the same strains that promoted plant growth. This suggests a role of this phytohormone in the higher root growth observed (Figs. 2a, b, c and 3d). Moreover, most of the cytokinins-related variables were associated in a cluster distinct to the growth-related variables, that was strongly negatively loaded in PC1. Accordingly, Sofo et al. (2011) observed a significant decrease in trans-zeatin and in dihydrozeatin, two of the most active cytokinins in plants shoots and roots, following the inoculation with T. harzianum T-22. However, as for other physiological processes, plant growth is usually not regulated by hormonal levels per se, but rather the complex balances between various hormones (Müller and Leyser 2011; Nordström et al. 2004). In our study, a significant increase in the auxin/cytokinins ratio ( 2 times higher) was found in shoot of plants inoculated with the growth-promoting isolates T-10, T-17 and T-22. This hormonal ratio is particularly important to control different developmental processes, such as the formation and maintenance of meristems (Ying-Hua et al. 2011) or adventitious shoot formation (Sriskandarajah et al. 2006). So it also might be related to the growth promotive effect observed in the seedling nursery.

Abscisic acid is related to plant development and defense against abiotic stress. It is known to fine-tune growth and development under stress conditions, such as cold, drought, and salinity (Christmann et al. 2006; De Smet et al. 2003; Raghavendra et al. 2010). Additionally, recent evidence shows that ABA also has a prominent role in resistance to biotic stress (Ton et al. 2009). In our study, the isolates that promoted plant growth also decreased the concentration of ABA in the melon shoots, which may reflect that the promotion of plant growth provided by these isolates might be accompanied by an improvement in plant fitness, as has been suggested for mycorrhizal associations regarding drought stress (Aroca et al. 2013; Ruiz-Lozano 2003).

Another major regulator of plant growth and development is ethylene (Etheridge et al. 2006; Nemhauser et al. 2006). It also is an important signalling molecule in plants under pathogen attack, resulting in plant growth inhibition (Abeles et al. 1992). In our study, the concentration of the ethylene precursor ACC was decreased by the isolates identified as T. harzianum (T-4 and T-7) as well as by T. harzianum T-22. 
Some Trichoderma isolates are known to produce ACC deaminase (ACCD), which reduces the availability of the ACC necessary for ET biosynthesis, which might result in plant root growth (Viterbo et al. 2010). Interestingly, in the PCA analysis, ABA and ACC content were placed in the same cluster as Fusarium wilt incidence, which highlights the potential physiological importance of alteration in ABA and ACC content by Trichoderma in the biocontrol activity of the tested Trichoderma strains.

The hormones JA and SA act as dominant primary signals in the regulation of defense responses in plants (Pieterse et al. 2009). Although several studies have shown a direct activation of JA- and SA-related signalling pathways in Trichoderma-colonized plants (Contreras-Cornejo et al. 2011; Martínez-Medina et al. 2011; Segarra et al. 2007), most examples point to a boosted activation of JA- and SAregulated defenses upon pathogen infection (Brotman et al. 2012; Mathys et al. 2012; Perazzolli et al. 2011). This priming phenomenon provides plants with a more efficient immune response upon pathogen attack (Conrath et al. 2006). Accordingly, in our study no direct activation of JA or SA pathways was observed in the shoots of Trichoderma-induced melon plants. Further analysis of hormonal content or expression of JA- or SA-inducible responses after pathogen infection are necessary to determine the ability of the different isolates to prime JA and/or SA plant defenses.

In summary, this study highlights the need to use a comprehensive functional approach to identify new isolates with biocontrol and growth promoting capabilities from the field. This approach should include not only the analyses of direct effects of the beneficial isolates on the fungal pathogen such as inhibition and mycoparasitism, but also indirect effects mediated by the interaction with the plant such as the alteration of plant hormonal homeostasis. It has been shown that although the most efficient isolate was the commercial strain T. harzianum $\mathrm{T}-22$, the natural isolate $T$. hamatum $\mathrm{T}-17$ was more efficient than any other selected natural isolate, as it was able to successfully control Fusarium wilt and to promote melon plant growth in the seeding nursery. Additionally, the data suggest that changes in phytohormone levels is one of the mechanisms by which selected Trichoderma isolates can interfere with plant physiology and improve plant fitness. Among the different hormones measured, PCA suggests an important role of auxin in controlling plant growth stimulation by Trichoderma, while plant-mediated mechanisms by which Trichoderma can control Fusarium wilt may be influenced by shoot content of ZR, ABA, and ACC.

Acknowledgments We thank Dr. Maria J. Pozo for useful comments on the manuscript. This research was supported by the CYCIT project AGL2010 21073 from the Spanish Ministry of Economy and Competitiveness, the Marie Curie Intra-European Fellowship FP7-PEOPLE2011-IEF no. 301662 (to AMM) and VIDI grant no. 11281 of the Netherlands Organization of Scientific Research (to SCMW).

\section{References}

Abeles FB, Morgan PW, Saltveit ME (1992) Ethylene in plant biology, Ed 2. Academic Press, New York

Albacete A, Ghanem ME, Martínez-Andújar C, Acosta M, SánchezBravo J, Martínez V, Lutts S, Dodd IC, Pérez-Alfocea F (2008) Hormonal changes in relation to biomass partitioning and shoot growth impairment in salinized tomato (Solanum lycopersicum L.) plants. J Exp Bot 59:4119-4131

Albacete A, Ghanem ME, Dodd IC, Pérez-Alfocea F (2010) Principal component analysis of hormone profiling data suggests an important role for cytokinins in regulating leaf growth and senescence of salinized tomato. Plant Signal Behav 5:45-48

Alfano G, Ivey MLL, Cakir C, Bos JIB, Miller SA, Madden LV, Kamoun $\mathrm{S}$, Hoitink HAJ (2007) Systemic modulation of gene expression in tomato by Trichoderma hamatum 382. Phytopathology 97:429-37

Anees M, Tronsmo A, Edel-Hermann V, Hjeljord LG, Héraud C, Steinberg C (2010) Characterization of field isolates of Trichoderma antagonistic against Rhizoctonia solani. Fungal Biol 114:691-701

Aroca R, Ruiz-Lozano JM, Zamarreño TM, Paz JA, García-Mina JM, Pozo MJ, López-Ráez JA (2013) Arbuscular mycorrhizal symbiosis influences strigolactone production under salinity and alleviates salt stress in lettuce plants. J Plant Physiol 170:47-55

Bae H, Roberts DP, Lim H, Strem MD, Park S, Ryu C, Melnick RL, Bailey BA (2011) Endophytic Trichoderma isolates from tropical environments delay disease onset and induce resistance against Phytophthora capsici in hot pepper using multiple mechanisms. Mol Plant-Microbe Interact 24:336-351

Benhamou N, Chet I (1996) Parasitism of sclerotia of Sclerotium rolfsii by Trichoderma harzianum: ultrastructural and cytochemical aspects of the interaction. Phytopathology 86:405-416

Benítez T, Rincón AM, Limón MC, Codón AC (2004) Biocontrol mechanisms of Trichoderma strains. Int Microbiol 7:249-260

Berg G (2009) Plant-microbe interactions promoting plant growth and health: perspectives for controlled use of microorganisms in agricultura. Appl Microbiol Biotechnol 84:11-18

Blaya J, López-Mondéjar R, Lloret E, Pascual JA, Ros M (2013) Changes induced by Trichoderma harzianum in suppressive compost controlling Fusarium wilt. Pestic Biochem Phys 107:112-119

Brotman Y, Lisec J, Méret M, Chet I, Willmitzer L, Viterbo A (2012) Transcript and metabolite analysis of the Trichoderma-induced systemic resistance response to Pseudomonas syringae in Arabidopsis thaliana. Microbiology 158:139-146

Chowdappa P, Mohan Kumar SP, Lakshmi MJ, Upreti KK (2013) Growth stimulation and induction of systemic resistance in tomato against early and late blight by Bacillus subtilis OTPB1 or Trichoderma harzianum OTPB3. Biol Control 6:109-117

Christmann A, Moes D, Himmelbach A, Yang Y, Tang Y, Grill E (2006) Integration of abscisic acid signalling into plant responses. Plant Biol 8:314-325

Conrath U, Beckers GJM, Flors V, García-Agustín P, Jakab G, Mauch F, Newman MA, Pieterse CMJ, Poinssot B, Pozo MJ, Pugin A, Schaffrath U, Ton J, Wendehenne D, Zimmerli L, Mauch-Mani B (2006) Priming: getting ready for battle. Mol Plant Microbe Interact 19:1062-1071

Contreras-Cornejo HA, Macías-Rodríguez L, Cortés-Penagos C, LópezBucio J (2009) Trichoderma virens, a plant beneficial fungus, enhances biomass production and promotes lateral root growth through an auxin-dependent mechanism in Arabidopsis. Plant Physiol 149:1579-1592

Contreras-Cornejo HA, Macías-Rodríguez L, Beltrán-Peña E, HerreraEstrella A, López-Bucio J (2011) Trichoderma-induced plant immunity likely involves both hormonal- and camalexin dependent mechanisms in Arabidopsis thaliana and confers resistance against necrotrophic fungus Botrytis cinerea. Plant Signal Behav 6:1554-1563 
De Smet I, Signora L, Beeckman T, Inzé D, Foyer CH, Zhang H (2003) An abscisic acid-sensitive checkpoint in lateral root development of Arabidopsis. Plant J 33:543-555

Donzelli BGG, Harman GE (2001) Interaction of ammonium, glucose, and chitin regulates the expression of cell wall-degrading enzymes in Trichoderma atroviride strain P1. Appl Environ Microbiol 67: 5643-5647

Elad Y, Chet I, Boyle P, Henis Y (1983) Parasitism of Trichoderma spp. on Rhizoctonia solani and Sclerotium rolfsii - scanning electron microscopy. Phytopathology 73:85-88

Etheridge N, Hall BP, Schaller GE (2006) Progress report: ethylene signaling and responses. Planta 223:387-39

Gravel V, Antoun H, Tweddell RJ (2007) Growth stimulation and fruit yield improvement of greenhouse tomato plants by inoculation with Pseudomonas putida or Trichoderma atroviride: possible role of indole acetic acid (IAA). Soil Biol Biochem 39:1968-1977

Hall TA (1999) BioEdit: a user-friendly biological sequence alignment editor and analysis program for windows 95/98/NT. Ncl Acid S 41:95-98

Harman GE (2000) Myths and dogmas of biocontrol. Changes perceptions derived from research on Trichoderma harzianum T22. Plant Dis $84: 377-393$

Harman GE, Howell CR, Viterbo A, Chet I, Lorito M (2004) Trichoderma species: opportunistic, avirulent plant symbionts. Nat Rev Microbiol 2:43-56

Harman GE, Björkman T, Ondik K, Shoresh M (2008) Changing paradigms on the mode of action and uses of Trichoderma spp. for biocontrol. Outlook Pest Manag 19:24-29

Hermosa R, Rubio MB, Cardoza RE, Nicolás C, Monte E, Gutiérrez S (2013) The contribution of Trichoderma to balancing the costs of plant growth and defense. Int Microbiol 16:69-80

Jung SC, Martínez-Medina A, Lopez-Raez JA, Pozo MJ (2012) Mycorrhiza-induced resistance and priming of plant defenses. J Chem Ecol 38:651-64

Linkies A, Müller K, Morris K, Turečková V, Wenk M, Cadman CSC, Corbineau F, Strnad M, Lynn JR, Finch-Savage WE, LeubnerMetzger G (2009) Ethylene interacts with abscisic acid to regulate endosperm rupture during germination: a comparative approach using Lepidium sativum and Arabidopsis thaliana. Plant Cell 21: 3803-3822

López-Mondéjar R, Ros M, Pascual JA (2011) Mycoparasitism-related genes expression of Trichoderma harzianum isolates to evaluate their efficacy as biological control agent. Biol Control 56:59-66

Lorito M, Woo LS, Harman GE, Monte E (2010) Translational research on Trichoderma: from'omics to the field. Annu Rev Phytopathol 48: 395-417

Marra R, Ambosino P, Carbone V, Vinale F, Woo SL, Ruocco M, Ciliento R, Lanzuise S, Ferraioli S, Soriente I, Gigante S, Turrà D, Fogliano V, Scala F, Lorito M (2006) Study of the three-way interaction between Trichoderma atroviride, plant and fungal pathogens using a proteome approach. Curr Genet 50:307-21

Martínez-Medina A, Pascual JA, Lloret E, Roldán A (2009a) Interactions between arbuscular mycorrhizal fungi and Trichoderma harzianum and their effects on Fusarium wilt in melon plants grown in seedlings nurseries. J Sci Food Agric 89:1843-1850

Martínez-Medina A, Roldán A, Pascual JA (2009b) Performance of a Trichoderma harzianum bentonite-vermiculite formulation against Fusarium wilt in seedling nursery melon plants. HortSci 44: 2025-2027

Martínez-Medina A, Roldán A, Albacete A, Pascual JA (2011) The interaction with arbuscular mycorrhizal fungi or Trichoderma harzianum alters the shoot hormonal profile in melon plants. Phytochemistry 72:223-229

Martínez-Medina A, Fernandez I, Sánchez-Guzmán MJ, Jung SC, Pascual JA, Pozo MJ (2013) Deciphering the hormonal signalling network behind the systemic resistance induced by Trichoderma harzianum in tomato. Front Plant Sci 4:206
Mathys J, De Cremer K, Timmermans P, Van Kerckhove S, Lievens B, Vanhaecke M, Cammue BPA, De Coninck B (2012) Genome-wide characterization of ISR induced in Arabidopsis thaliana by Trichoderma hamatum T382 against Botrytis cinerea infection. Front Plant Sci 3:108

Mok DWS, Mok MC (2001) Cytokinin metabolism and action. Annu Rev Plant Physiol Plant Mol Biol 52:89-118

Monte E (2001) Understanding Trichoderma: between biotechnology and microbial ecology. Int Microbiol 4:1-4

Mukherjee PK, Horwitz BA, Kenerley CM (2012) Secondary metabolism in Trichoderma - a genomic perspective. Microbiology 158: $35-45$

Müller D, Leyser O (2011) Auxin, cytokinin and the control of shoot branching. Ann Bot 107:1203-1212

Nemhauser JL, Hong F, Chory J (2006) Different plant hormones regulate similar processes through largely nonoverlapping transcriptional responses. Cell 126:467-475

Nordström A, Tarkowski P, Tarkowska D, Norbaek R, Åstot C, Dolezal K, Sandberg G (2004) Auxin regulation of cytokinin biosynthesis in Arabidopsis thaliana: a factor of potential importance for auxincytokinin-regulated development. Proc Natl Acad Sci U S A 101: 8039-8044

Ortiz A, Orduz S (2000) In vitro evaluation of Trichoderma and Gliocladium antagonism against the symbiotic fungus of the leafcutting ant Atta cephalotes. Mycopathologia 150:53-60

Papavizas GC, Lumsden RD (1982) Improved medium for isolation of Trichoderma spp. from soil. Plant Dis 66:1019-1020

Perazzolli M, Roatti B, Bozza E, Pertot I (2011) Trichoderma harzianum T39 induces resistance against downy mildew by priming for defense without costs for grapevine. Biol Control 58:74-82

Pieterse CMJ, Leon-Reyes A, Van der Ent S, Van Wees SCM (2009) Networking by small-molecule hormones in plant immunity. Nat Chem Biol 5:308-316

Raghavendra AS, Gonugunta VK, Christmann A, Grill E (2010) ABA perception and signalling. Trends Plant Sci 15:395-401

Ramot O, Cohen-Kubiec R, Chet I (2000) Regulation of $\beta-1,3-$ glucansase by carbon starvation in the mycoparasite Trichoderma harzianum. Mycol Res 104:415-42

Ruiz-Lozano JM (2003) Arbuscular mycorrhizal symbiosis and alleviation of osmotic stress. new perspectives for molecular studies. Mycorrhiza 13:309-317

Segarra G, Casanova E, Bellido D, Odena MA, Oliveira E, Trillas I (2007) Proteome, salicylic acid, and jasmonic acid changes in cucumber plants inoculated with Trichoderma asperellum strain T34. Proteomics 7:3943-52

Shoresh M, Harman GE (2008) The molecular basis of shoot responses of maize seedlings to Trichoderma harzianum T22 inoculation of the root: a proteomic approach. Plant Physiol 147:2147-63

Shoresh M, Yedidia I, Chet I (2005) Involvement of jasmonic acid/ethylene signaling pathway in the systemic resistance induced in cucumber by Trichoderma asperellum T203. Phytopathology 95: $76-84$

Shoresh M, Harman GE, Mastouri F (2010) Induced systemic resistance and plant responses to fungal biocontrol agents. Annu Rev Phytopathol 48:21-43

Simon S, Petrasek J (2011) Why plants need more than one type of auxin. Plant Sci 180:454-460

Sofo A, Scopa A, Manfra M, De Nisco M, Tenore G, Troisi J, Di Fiori R, Novellino E (2011) Trichoderma harzianum strain T-22 induces changes in phytohormone levels in cherry rootstocks (Prunus cerasus $\mathrm{x} P$. canescens). Plant Growth Regul 65:421-425

Sofo A, Tataranni G, Xiloyannis C, Dichio B, Scopa A (2012) Direct effects of Trichoderma harzianum strain T-22 on micropropagated shoots of GiSeLa6 (Prunus cerasus x P. canescens) rootstock. Environ Exp Bot 76:33-38 
Sriskandarajah S, Prinsen E, Motyka V, Dobrev PI, Serek M (2006) Regenerative Capacity of Cacti Schlumbergera and Rhipsalidopsis in Relation to Endogenous Phytohormones, Cytokinin Oxidase/ Dehydrogenase, and Peroxidase Activities. J Plant Growth Regul 25:79-88

Tamura K, Peterson D, Peterson N, Stecher G, Nei KS (2011) MEGA5: molecular evolutionary genetics analysis using maximum likelihood, evolutionary distance, and maximum parsimony methods. Mol Biol Evol 28:2731-2739

Ton J, Flors V, Mauch-Mani B (2009) The multifaceted role of ABA in disease resistance. Trends Plant Sci 14:310-317

Tucci M, Ruocco M, De Masi L, De Palma M, Lorito M (2011) The beneficial effect of Trichoderma spp. on tomato is modulated by the plant genotype. Mol Plant Pathol 12:341-354

Van Wees SCM, Van Der Ent S, Pieterse CMJ (2008) Plant immune responses triggered by beneficial microbes. Curr Opin Plant Biol 11: 443-448

Vinale F, Sivasithamparam K, Ghisalberti EL, Marra R, Woo SL, Lorito M (2008) Trichoderma plant- pathogen interactions. Soil Biol Biochem 40:1-10

Viterbo A, Montero M, Ramot O, Friesem D, Monte E, Llobell A, Chet I (2002) Expression regulation of the endochitinase chit36 from
Trichoderma asperellum (T. harzianum T-203). Curr Genet 42: 114-22

Viterbo A, Landau U, Kim S, Chernin L, Chet I (2010) Characterization of ACC deaminase from the biocontrol and plant growth-promoting agent Trichoderma asperellum T203. FEMS Microbiol Lett 305:42-8

Werner T, Motyka V, Strnad M, Schmülling T (2001) Regulation of plant growth by cytokinin. Proc Natl Acad Sci U S A 98:10487-10492

White TJ, Bruns T, Lee S, Taylor J (1990) Amplification and direct sequencing of fungal ribosomal RNA genes for phylogenetics. In: Innis MA, Gelfand DH, Sninsky JJ, White TJ (eds) PCR Protocols. A guide to methods and applications. Academic Press, San Diego, pp 315-322

Woo SL, Scala F, Ruocco M, Lorito M (2006) The molecular biology of the interactions between Trichoderma spp., phytopathogenic fungi, and plants. Phytopathology 96:181-185

Ying-Hua S, Yu-Bo L, Xian-Sheng Z (2011) Auxin-cytokinin interaction regulates meristem development. Mol Plant 4:616-625

Zeilinger S, Galhaup C, Payer K, Woo SL, Mach RL, Fekete C, Lorito M, Kubicek CP (1999) Chitinase gene expression during mycoparasitic interaction of Trichoderma harzianum with its host. Fungal Genet Biol 26:131-40

Zhang Z, Schwartz S, Wagner L, Miller W (2000) A greedy algorithm for aligning DNA sequences. J Comput Biol 7:203-214 